\title{
Using a Novel Mucor Indicus CBS 226.29 ET for Biosynthesis of Gold Nanoparticles and Applying Them in Nanoremediation of Azo Dyes
}

Alshehri ANZ*

Department of Biology, University College in Al-Jummum, Umm Al-Qura University, Makkah, 21955, Saudi Arabia

Received: 25 January, 2018; Accepted:15 February, 2018; Published: 05 April, 2018

*Corresponding author: Alshehri ANZ, Department of Biology, University college in Al-Jummum, Umm Al-Qura University, Makkah, 21955, Saudi Arabia, Tel: +00966563708094; E-mail: anshehri@uqu.edu.sa

\begin{abstract}
Synthesis of nanoparticles by microorganisms may offer an environmentally friendly and affordable alternative to traditional physical and chemical methods. The microbial synthesis of nanoparticles is an approach based on green chemistry which mutually connects microbial biotechnology and nanotechnology. Fungus of Mucor indicus CBS 226.29 ET, in this work was used to synthesize gold nanoparticles (AuNPs). A surface level Plasmon resonance peak was observed at $500 \mathrm{~nm}$ by UV-bis spectra of AuNPs. Images of AuNP via transmission electron microscope exhibited various shapes and dispensability characteristics. The synthesis of AuNPs was optimum at the conditions $1.5 \mathrm{mM} / \mathrm{L}$ of $\mathrm{HAuCl}_{4}, 0.6 \mathrm{~g}$ biomass, and $\mathrm{pH}$ range 7-11. The Decolorization of different azo dyes was catalyzed efficiently with the bio-AuNPs, and a new microbial resource candidate was thus demonstrated for these AuNPs through green synthesis, along with a potential bio-AuNP application for Decolorization of azo dyes.
\end{abstract}

Keywords: Azo dyes; Biosynthesis; Decolorization; Gold nanoparticles; Mucor indicus

\section{Introduction}

Superior characteristics of nanomaterials relative to bulk materials give them a potential for application in every aspect of our lives [1]. The high oxidation resistance, stability and biocompatibility of gold nanoparticles (AuNPs) make them particularly more attractive than all other nanomaterials [2-4] many traditional physical and chemical methods are available for the synthesis of AuNPs, their stability and the concern over using toxic chemicals during production of AuNPs is considered problematic $[5,6]$ hence an urgent need exists for developing an eco-friend process for synthesizing AuNPs. Compared to chemical and physical methods, biological methods for the synthesis of AuNPs is more reliable and eco friendly [7]. Several microorganisms can synthesize AuNPs, including bacteria, fungi and yeast [7-9]. Fungi offer great advantages for synthesizing AuNPs, and are therefore considered to be most suitable for high nanoparticles production [10,11]. In particular, fungi secrete proteins and secondary metabolites in large quantity and extracellularly, which can then the separated easily without recourse to process of downstream [12]. Nevertheless, AuNP synthesis has only been investigated for fewer than 30 fungal species [9]. More fungi isolates need to be discovered for the biosynthesis of AuNPs and to overcome the major challenges related to shape, size and disparity. These three aforementioned major challenges have been shown in some reports to be affected by biomass and substrate concentrations and $\mathrm{pH}$ value [1315]. The control of the size factor in AuNPs biosynthesis is very important given that particle size affects the nanomaterials properties directly. With respect to dyes, the largest chemical class is azo dyes which exhibit great variety in structure and color [16], thus serious and huge damage could be occurred to the environment by disposing effluents containing azo dyes. In particular, since dyes reflect and absorb sunlight due to their color content, wastewater can become contaminated which can thereby disrupt photosynthesis and affect aquatic organisms growth [17]. Some solutions for treating azo dye pollutants using green methods have been reported. For instance, some of microorganisms have been reported to be capable of treating azo dye pollutants efficiently such as Pseudomonas, Shewanella and Bacillus [18-20]. The degradation of pollutants could be improved efficiently by using AuNPs in process of Nanoremediation [21]. Reports on degradation of dyes by biogenic AuNPs are very rare.

In this work, the fungus $M$. indicus CBS 226.29 ET was used to synthesize AuNPs as eco-friendly method, and an UV-Vis spectrophotometer and Transmission Electron Microscopy (TEM) were used to determine the AuNPs characteristics. The optimum conditions of different parameters for biosynthesis of AuNPs were ascertained, and various azo dyes underwent Decolorization to evaluate catalytic characteristics of the bioAuNPs being prepared.

\section{Materials and methods \\ Chemicals and medium}

The chemicals used in this study (purity 99\%) were 
obtained from SIGMA ALDRICH Chemicals, USA. The selection and cultivation medium was a modified form of Martin Broth (MMB) at pH 7 consisting of (g/L): $1.0\left(\mathrm{NH}_{4}\right)_{2} \mathrm{SO}_{4}, 1.0 \mathrm{KH}_{2} \mathrm{PO}_{4}, 0.5$ $\mathrm{MgSO}_{4} \cdot 7 \mathrm{H}_{2} \mathrm{O}$, and 1.0 glucose. The solid medium contained $2.0 \%$ (w/v) agar in MMB, and for isolating fungi strain $50 \mathrm{mg} / \mathrm{L}$ of each terramycin and tetracycline were added as selective pressure. Autoclaving of the media at a temperature of $115^{\circ} \mathrm{C}$ was done for 15 minutes prior to use.

\section{Isolation and identification of fungus}

Soil samples contaminated with heavy metals were collected from an industrial area in Jeddah-Saudi Arabia the samples were then diluted serially prior to spreading onto MMB agar plates. Following a 4 day period of incubation at $30^{\circ} \mathrm{C}$, selected colonies were transferred into $25 \mathrm{~mL} \mathrm{MMB}$ medium and cultivated for a further period of 3 days at $30^{\circ} \mathrm{C}$ and at shaking of $150 \mathrm{r} / \mathrm{min}$. A line of Lacto Phenol Cotton Blue (LPCB) was then smeared on a slide and examined under a confocal microscope. A sample of the fungal strain was picked up using adhesive tape and placed onto the LPCB for further examination by a confocal microscope (Leica, Wasteland, Germany). Subsequently, closer examination of the fungal strain was undertaken utilizing Scanning Electron Microscopy (SEM, JSM- 5410LV, JEOL Ltd., Japan) as described by [22]. Following a one month period of screening and enrichment, a single colony of $M$. indicus was selected to undergo further characterization and identification through 26S rRNA gene sequence analysis. Amplification of the 26S rRNA gene from DNA of the isolated fungus was achieved by Polymerase Chain Reaction (PCR), and sequencing of the PCR product was done by Center of Excellence in Genomic medicine Research-KAU (Saudi Arabia). The sequence was compared with those on record at GenBank using the BLAST program, and related sequences were aligned by using Clustal X (1.8) for constructing a Phylogenetic tree by the Neighbor -joining method using MEGA (version 5.1) with 1000 bootstrap replicates [23].

\section{Synthesis of AuNPs}

Fungus M. indicus CBS 226.29 ET was cultivated over a 2-day period in $100 \mathrm{~mL} \mathrm{MMB} \mathrm{medium} \mathrm{at} 30^{\circ} \mathrm{C}$ and shaking at $150 \mathrm{r} /$ min. Following incubation, the biomass of $M$. indicus CBS 226.29 ET was prepared by filtration and washing using sterile distilled water three times. An appropriate wet biomass concentration was re-suspended in distilled water prior to further incubation over a period of 40 hours at $30^{\circ} \mathrm{C}$ with $1.0 \mathrm{mM} / \mathrm{L} \mathrm{HAuCl}_{4}$, and a control experiment was also carried out without using any biomass. The following procedure was applied to investigate influences of concentrations of $\mathrm{HAuCl}_{4}$ and biomass, as well as, $\mathrm{pH}$ values on synthesis of AuNPs: (1) Addition of $\mathrm{HAuCl}_{4}$ in a range of concentrations $(0.1,0.5,1.0,1.5,2.0,5.0 \mathrm{mM} / \mathrm{L})$ to the $0.1 \mathrm{~g}$ biomass solutions with a final volume of $4 \mathrm{~mL}$. (2) Suspension of biomass with a range of mass $(0.1,0.2,0.3,0.4,0.5,0.6 \mathrm{~g})$ in sterile distilled water $(4 \mathrm{~mL})$ were incubated with $2.0 \mathrm{mM} / \mathrm{L}$ of $\mathrm{HAuCl}_{4}$. (3) Adjustment of the reaction solution to $\mathrm{pH}(3,5,7,9,11)$ was done by $\mathrm{HCl}$ and $\mathrm{NaOH}$. These aforementioned experiments were carried out for 40 hours at a temperature of $30^{\circ} \mathrm{C}$.

\section{Characterization of AuNPs}

Examination of AuNPs formation was done by visually observing color changes of the suspensions before monitoring with a UV-Vis spectrophotometer (Metash UV-9000, China) to record spectra ranging between $400 \mathrm{~nm}$ and $800 \mathrm{~nm}$ at $1 \mathrm{~nm}$ resolution. AuNP morphology was then characterized using a Transmission Electron Microscope (TEM) (Tecnai G2 Spirit-FEI, Netherlands) with $120 \mathrm{kV}$ accelerating voltage. Samples of $15 \mu \mathrm{L}$ were dropped for the TEM analysis onto a carbon coated copper grid, which was then dried at room temperature prior to the analysis.

\section{Decolorization of azo dyes by bio-AuNPs}

The M. indicus CBS 226.29 ET and AuNPs were subjected to ultrasonication process (Ultrasonic Processor CPX 750, USA) to produce bio-AuNPs for Decolorization of azo dyes. Acid, reactive and cationic azo dyes were used to demonstrate potential catalytic activity of the bio-AuNPs in Decolorization of azo dyes. After addition of dyes to $50 \mathrm{mg} / \mathrm{L}$ of the bio-AuNP solution, and incubation on the shaker at $30^{\circ} \mathrm{C}$ and $150 \mathrm{r} / \mathrm{min}$, a control experiment was conducted using ultrasonicated $M$. indicus CBS 226.29 E cells under identical conditions instead of bio-AuNPs for Decolorization of $50 \mathrm{mg} / \mathrm{L}$ of Acid Brilliant Scarlet GR. The influence of initial concentration of Acid Brilliant Scarlet GR (25, 50, 100, $200 \mathrm{mg} / \mathrm{L}$ ) on Decolorization process was examined.

\section{Analytical methods}

The Absorption wavelength of azo dyes $\left(\lambda_{\max }\right)$ was scanned as characteristic to monitor the decolorization process using a UVVis spectrophotometer following centrifugation $(10,000 \mathrm{~g})$ for 5 minutes at varying time intervals. The following equation was used to calculate the Decolorization proportion (1):

Decolorization $(\%)=\left(A_{0}-A_{1}\right) /=A_{0} \times 100$

Where $A_{0}$ and $A_{1}$ represent the dye's initial and final absorbance respectively

High Performance Liquid Chromatography-Mass Spectrometry (HPLC-MS) was used to detect the intermediate products, which resulted from reduction of Acid Brilliant Scarlet GR by bio-AuNPs, as described earlier (Tan et al., 2013).

\section{Results and discussion}

\section{Isolation and identification of $M$. indicus}

A fungal strain identified as $M$. indicus, was isolated from a sample of contaminated soil with heavy metals taken from Jeddah-Saudi Arabia. Initial screening of the fungal specimen on its third day of growth prepared using adhesive tape revealed highly grown hyphae, sporangium-like structures and spores under confocal microscope (Figure 1). For finer details, the fungal strain was examined by SEM. The hyphae, collumella, sporangium, sporangiospore and collarette (Figure 2) of the strain were clearly observed. All of these notable features attributed to the genus Mucor, and based on the morphological specifications, it was clear that the fungal strain would belong to the genus Mucor. Morphological specifications are usually sufficient to determine 


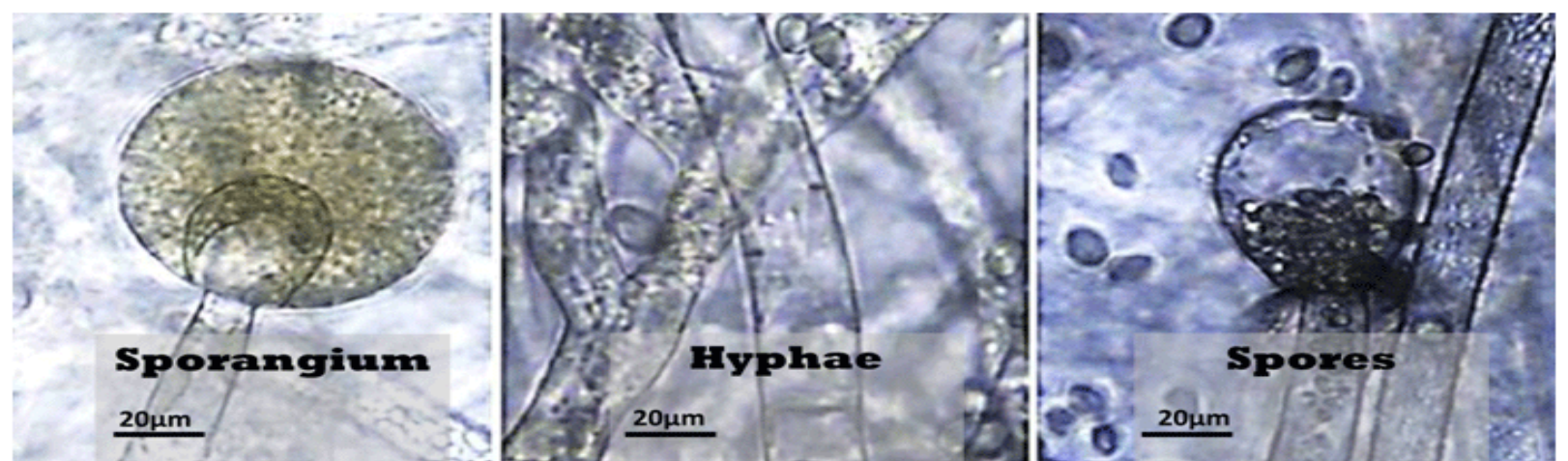

Figure 1: Images of the isolated fungal strain under confocal microscope show the morphological features.

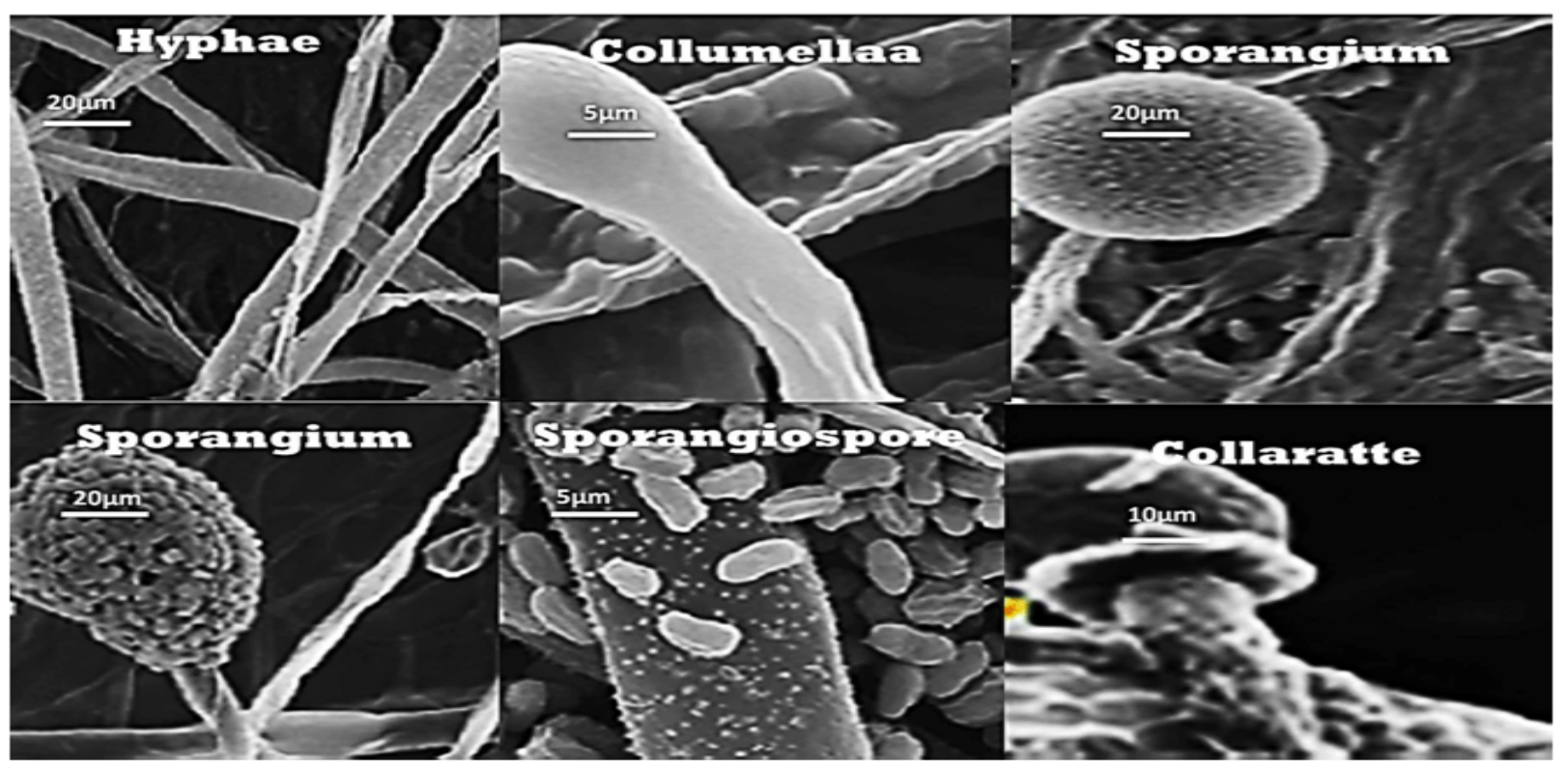

Figure 2: SEM images of the isolated fungal strain show the morphological features.

a strain's genus level, but rDNA sequencing is necessary for distinguishing microorganisms at the level of species. Analysis of the $26 \mathrm{~S}$ rRNA gene sequence showed evidence of $100 \%$ homology of the fungus to $M$. indicus (Genebank accession number CBS 226.29 ET), consequently the identification of the fungus was $M$. indicus CBS 226.29 ET. The relationship between $M$. indicus CBS 226.29 ET and other strains was demonstrated in the phylogenic tree as it is depicted in Figure 3.

\section{Biosynthesis of AuNPs}

Biosynthesis of the AuNPs was done by incubating $M$. indicus CBS 226.29 ET with $\mathrm{HAuCl}_{4}$. After $4 \mathrm{~h}$ of incubation, the reaction mixture changed from a pale yellowish color to violet (Figure 4). This indicated the formation of gold nanoparticles, and the color change was indicative of a coherent oscillation of surface nanoparticles of electron gas resulting in Surface Plasmon Resonance (SPR) [9]. An absorption peak was observed at 500 $\mathrm{nm}$ by UV-vis spectrum of the reaction solution (Figure 5).
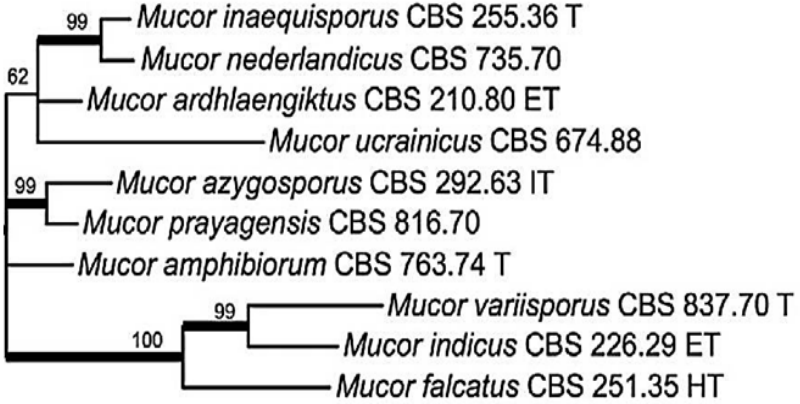

Figure 3: Phylogenetic tree of M. indicus CBS 226.29 ET and related species

This was indicative of AuNPs formation [24]. The dispersion of synthesized AuNPs was characterized by a diversity of shapes, as shown by the TEM images. The predominant shape was the 


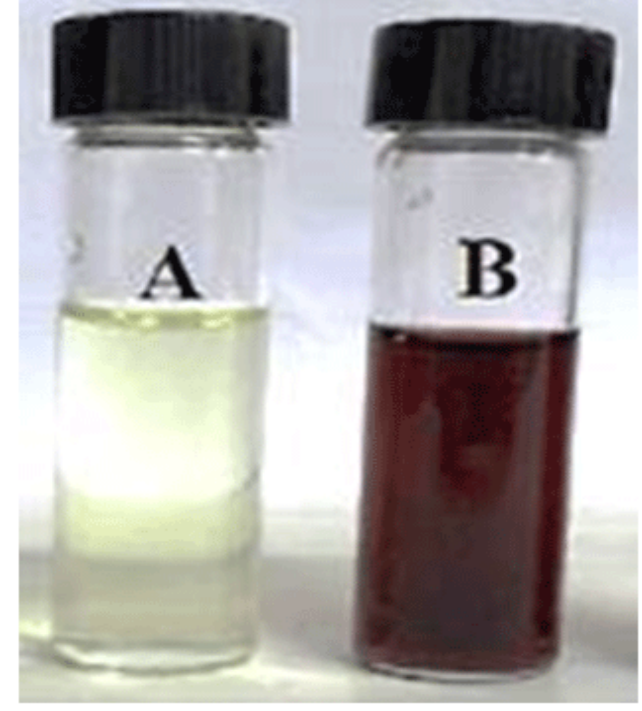

Figure 4: The pale yellowish reaction mixture A changed to violet color $\mathrm{B}$, indicating the formation of gold nano particles.

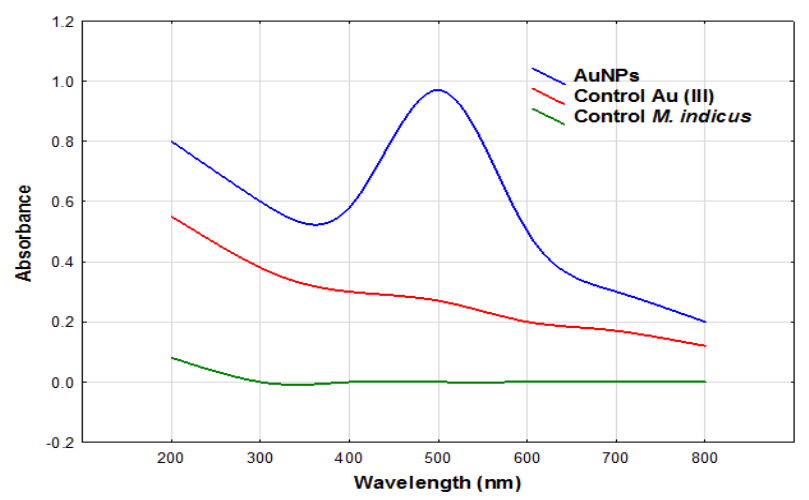

Figure 5: UV-vis spectra of the dispersed AuNPs synthesized by strain M. indicus CBS $226.29 \mathrm{ET}$ after $40 \mathrm{~h}$ incubation, $\mathrm{HAuCl}_{4}$ solution, and control strain $M$. indicus CBS 226.29 ET.

sphere, but triangles and hexagons were also observed, and with respect to size, spherical particles were found to be smaller relative to the triangles and polygons (Figure 6). As a genus, the fungal strain $M$. indicus is known to be capable of secreting a range of extracellular enzymes and metabolites in varying amounts. This advantage makes it a highly suitable candidate for producing metal nanoparticles on an industrial scale $[25,26]$. The results also confirm $M$. indicus to have exemplary ability in the biosynthesis of AuNPs, which makes them further suitable for AuNPs biosynthesis as a potential microbial resource.

\section{Effect of $\mathrm{HAuCl}_{4}$ concentrations}

Figure 7 depicts the effects of the $\mathrm{HAuCl}_{4}$ concentrations $(0.5$, 1.5 , and $2.0 \mathrm{mM} / \mathrm{L}$ ) on the synthesis of AuNPs. A violet or pink color was observed for those suspensions treated with $\mathrm{HAuCl}_{4}$ for $40 \mathrm{~h}$. Absorption peaks were recorded at $500 \mathrm{~nm}$ confirming AuNPs formation [27], and when the concentration was $1.5 \mathrm{mM} / \mathrm{L}$, a strong Surface Plasmon Resonance (SPR) band was observed at
$500 \mathrm{~nm}$. Thus the optimal concentration of $\mathrm{HAuCl}_{4}$ was $1.5 \mathrm{mM} / \mathrm{L}$ for AuNPs biosynthesis. Increasing the $\mathrm{HAuCl}_{4}$ concentration to $5.0 \mathrm{mM} / \mathrm{L}$ resulted the synthesis of gold particles at large sizes was achieved by attaching on the tube wall. Large particle formation was likely to be due to a lack of biomolecules necessary for capping the synthesized nanoparticles and their efficient stabilization [21]. The use of Verticillium luteoalbum for AuNPs synthesis resulted in a similar observation. A concentration of $\mathrm{HAuCl}_{4}$ below $500 \mathrm{mg} / \mathrm{L}$ resulted in a particle size of around $20 \mathrm{~nm}$, whereas a concentration above $500 \mathrm{mg} / \mathrm{L}$ resulted in a distribution of the particle size from $50 \mathrm{~nm}$ to several hundred nanometers. Furthermore, the cells exhibited massive particle aggregates [13].

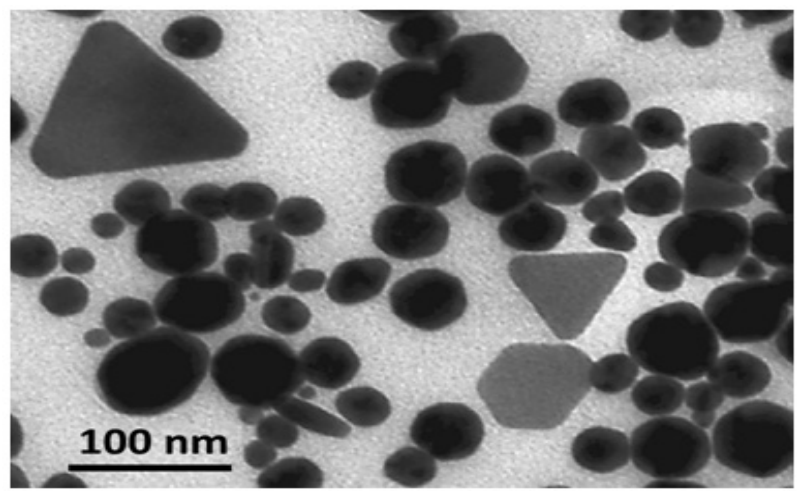

Figure 6: The TEM image of AuNPs synthesized by strain M. indicus CBS 226.29 ET

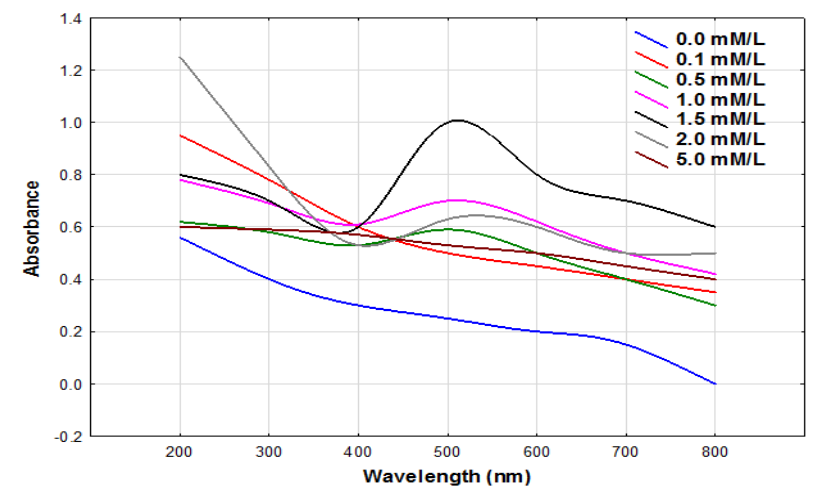

Figure 7: UV-Vis spectra of the dispersed AuNPs synthesized under different concentrations of $\mathrm{HAuCl}_{4}(0.1,0.5,1.0,1.5,2.0,5.0 \mathrm{mM})$ in reaction solutions.

\section{Effect of biomass concentrations}

Figure 8 illustrates effects of the biomass concentrations on the synthesis of AuNPs. The color of all the reactive solutions changed to purple indicating synthesis of AuNPs at varying biomass concentrations. When using $0.1 \mathrm{~g}$ of biomass, a broadening of the Surface Plasmon Resonance (SPR) absorbance of reaction solution was displayed at the maximum wavelength of $500 \mathrm{~nm}$. This broadness may be attributed to large formations of AuNPs (triangle, hexagon and sphere) causing a transverse interaction of radiance $[28,29]$. Notably, when the biomass concentration 
was increased to $0.6 \mathrm{~g}$, a narrowing of the absorbance band was evident along with a blue shift. This may be explained as higher biomass concentrations providing more biomolecules thereby reducing gold ions and allowing for the synthesis of smaller sized particles, and hence the blue shift in absorption peak levels [30].

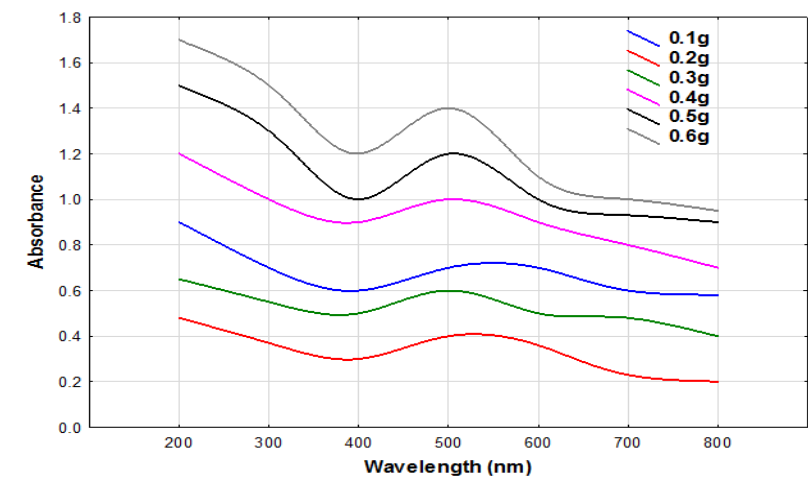

Figure 8: UV-Vis spectra of the dispersed AuNPs synthesized under different concentrations of strain $M$. indicus CBS 226.29 ET biomass (0.1, $0.2,0.3,0.4,0.5,0.6 \mathrm{~g}$ ) in reaction solutions.

\section{Effect of pH}

The influence of $\mathrm{pH}$ values on synthesis of AuNPs is illustrated in Figure 9. An improvement in the average of AuNP synthesis was spotted when increasing the $\mathrm{pH}$ value of solutions. In a condition of extreme alkalinity ( $\mathrm{pH} \mathrm{12),} \mathrm{the} \mathrm{color} \mathrm{was} \mathrm{observed}$ to change within $2 \mathrm{~h}$. compared to $4 \mathrm{~h}$. when in a condition of extreme acidity ( $\mathrm{pH} 3$ ). The SPR band was strongly and sharply defined when in the range $\mathrm{pH} 7$ to 11 , but relatively broader at $\mathrm{pH}$ 3. These sharpness and strength at $\mathrm{pH} 7$ to 11 , interpreted as a better performance at synthesis of AuNPs, may be explained as being due to a higher stability of capping proteins, which the M. indicus CBS 226.29 ET secreted them under either alkaline or neutral conditions, whereas under acidic conditions, protonation of the carboxylic groups may occur [31,15] also observed this phenomenon, thereby confirming the ability of the cell free extract of Trichoderma viride to synthesize AuNPs, which took place at $\mathrm{pH} 7$ and $\mathrm{pH} 9$, but not $\mathrm{pH} 5$.

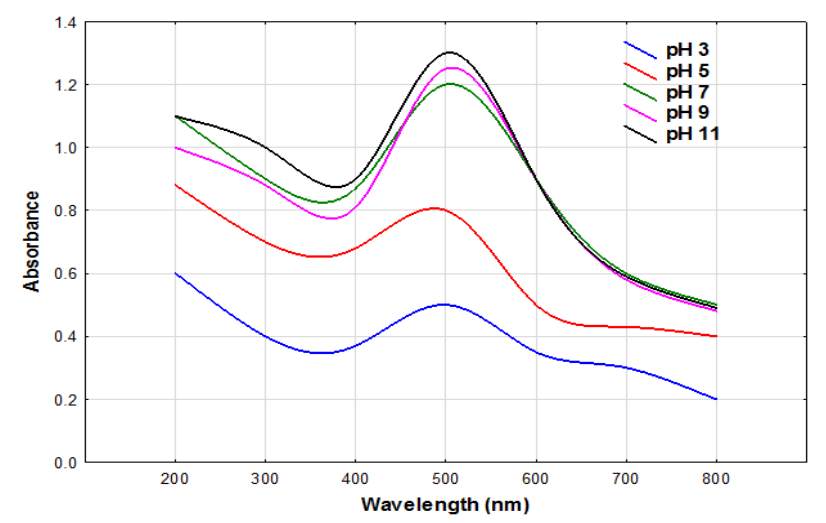

Figure 9: UV-Vis spectra of the dispersed AuNPs synthesized under different conditions of $\mathrm{pH}(3,5,7,9,11)$ in reaction solutions.

\section{Application of bio-AuNPs for azo dye Decolorization}

Employing of bio-AuNPs in nanoremediation process as a decolorative to remove azo dyes was conducted. Figure 10 displays the the Decolorization of various azo dyes due to bioAuNPs. This includes four acid azo dyes by rate $81 \%-96 \%$ in $100-120 \mathrm{~min}$, three reactive azo dyes by rate $45 \%-70 \%$ in $100-180 \mathrm{~min}$, and one cation azo dye by rate $39 \%$ in $180 \mathrm{~min}$. The maximum efficiency in Decolorization was for Acid Brilliant Scarlet GR at $94.7 \%$. This was therefore selected as a model dye in further experimental investigation. Figure 11 displays different concentrations of Acid Brilliant Scarlet GR undergoing Decolorization processes by the bio-AuNPs. The efficiency of Acid Brilliant Scarlet GR in Decolorization was found to be greater than $90 \%$ over $40 \mathrm{~min}$ for a dye concentration of $25 \mathrm{mg} / \mathrm{L}$. When this concentration was increased to $50 \mathrm{mg} / \mathrm{L}$, the high efficiency over $90 \%$ in 100 min was retained, but ultrasonicated M. indicus CBS 226.29 ET cells decolored only 4.8\% of Acid Brilliant Scarlet GR (Figure 12). AuNPs may therefore enhance Decolorization greatly with the use of high catalytic activities. Analysis of Acid Brilliant Scarlet GR Decolorization byproducts by HPLC-MS revealed

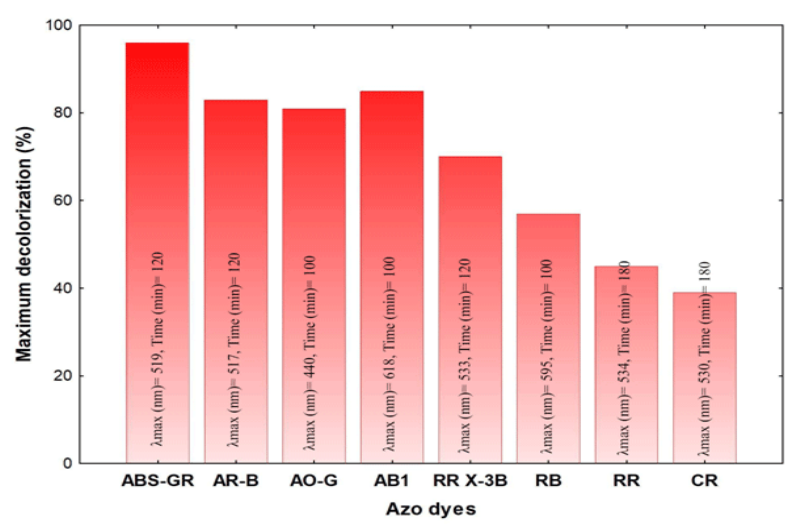

Figure 10: Decolorization of azo dyes $(50 \mathrm{mg} / \mathrm{L})$ by bio-AuNPs. Acid Brilliant Scarlet GR (ABS-GR), Acid Red B (AR-B), Acid Orange G (AO-G), Acid Black 1 (AB1), Reactive Red X-3B (RR X-3B), Reactive Black (RB), Reactive Red (RR), Cation Red (CR).

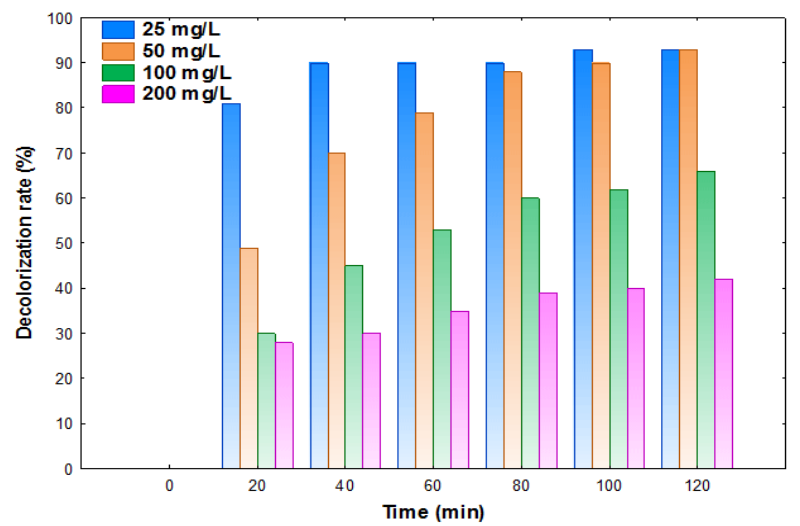

Figure 11: Effects of initial concentration $(25,50,100,200 \mathrm{mg} / \mathrm{L})$ of Acid Brilliant Scarlet GR on Decolorization 


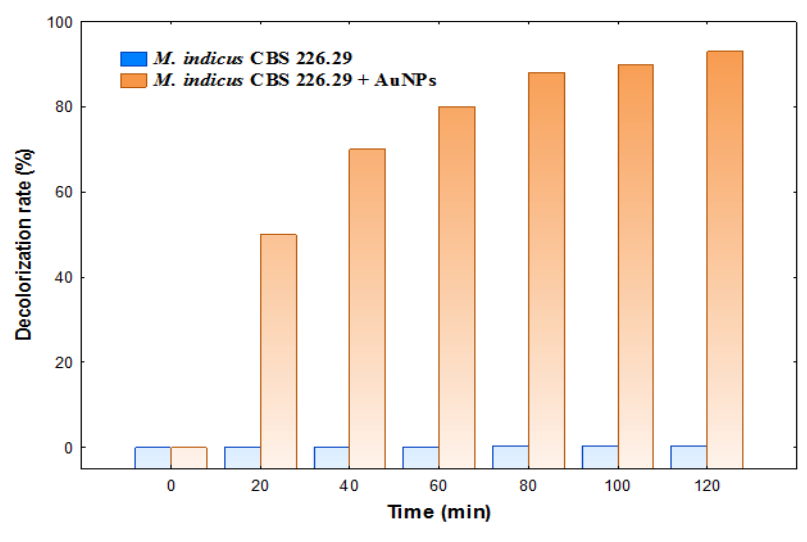

Figure 12: The decolorization rate of Acid Brilliant Scarlet GR (50 $\mathrm{mg} / \mathrm{L}$ ) by ultrasonicated M. indicus CBS 226.29 ET cells and bio-AuNPs (mixture of AuNPs and ultrasonicated M. indicus CBS 226.29 ET cells).

two candidates functioning as Decolorization intermediates, namely 3, 7-Dihydroxyoctahydronaphthalene- 2,6-dione (I) corresponding to a mass peak of $215.1658([\mathrm{M}-\mathrm{H}+])$, and naphthol (II) that was emphasized with $\mathrm{m} / \mathrm{z}$ ion peak of 143.1078 $([\mathrm{M}-\mathrm{H}+])$. Previous reports have also detected the same two as intermediates of Acid Brilliant Scarlet GR degradation [32-34] indicated that the first step of azo dye degradation was reductive cleavage of azo groups $(-\mathrm{N}=\mathrm{N}-)$, however, this study did not detect 1-aminonaphthylene-2- hydroxy-3, 6-disulfonic acid (III) as corresponding amines of Acid Brilliant Scarlet GR to which it was initially transformed. Oxidation of the intermediate (III) was likely to have been under aerobic conditions to the compound (I) [33]. The generation of intermediate (II) from product (I) was likely a result of the removal of two aldehyde groups and a hydroxyl group. These results indicate a potentially effective application of bio-AuNPs for azo dye Decolorization.

\section{Conclusions}

In this work, an investigation was conducted to synthesize AuNPs via eco-friendly resource by $M$. indicus CBS 226.29 ET as a newly isolated fungal strain. Characteristics of the biosynthesized AuNPs were ascertained by UV-vis and TEM analysis, and further experiments were made to investigate the effects of certain parameters $\left(\mathrm{HAuCl}_{4}\right.$ concentrations, biomass concentrations and $\mathrm{pH}$ ) on AuNPs synthesis to obtain useful data on oriented biosynthesis of AuNPs. Furthermore, the observations of nanoremediation of various azo dyes as applications of bio-AuNPs indicated good potential application of the biogenetic AuNPs in the Decolorization of azo dyes. This work should provide a more insight for using fungi as microbial resource in AuNPs synthesis.

\section{References}

1. Kuang Y, Zhou Y, Chen Z, Megharaj M, Naidu R. Impact of Fe and $\mathrm{Ni} / \mathrm{Fe}$ nanoparticles on biodegradation of phenol by the strain Bacillus fusiformis (BFN) at various pH values. Bioresour Technol. 2013;136:588-594. doi:10.1016/j.biortech.2013.03.018

2. Shukla R, Bansal V, Chaudhary M, Basu A, Bhonde RR, Sastry M. Biocompatibility of gold nanoparticles and their endocytotic fate inside the cellular compartment: a microscopic overview. Langmuir.

\section{5;21(23):10644-10654. DOI: 10.1021/la0513712}

3. Bhumkar DR, Joshi HM, Sastry M, Pokharkar VB. Chitosan reduced gold nanoparticles as novel carriers for transmucosal delivery of insulin. Pharm Res. 2007;24(8):1415-1426. DOI: 10.1007/s11095007-9257-9

4. Gong JL, Mullins CB. Surface science investigations of oxidative chemistry on gold. Acc Chem Res. 2009;42(8):1063-1073. DOI: 10.1021/ar8002706

5. Narayanan KB, Sakthivel N. Biological synthesis of metal nanoparticles by microbes. Adv Colloid Interf Sci. 2010;156(1-2):1-13. DOI: 10.1016/j.cis.2010.02.001

6. Das SK, Das AR, Guha AK. Microbial synthesis of multishaped gold nanostructures. Small. 2010;6(9):1012-1021. doi: 10.1002/ smll.200902011

7. Zhang X, Yan S, Tyagi RD, Surampalli RY. Synthesis of nanoparticles by microorganisms and their application in enhancing microbiological reaction rates. Chemosphere. 2011; 82(4):489-494. doi:10.1016/j. chemosphere.2010.10.023

8. Shedbalkar U, Singh R, Wadhwani S, Gaidhani, S, Chopade BA. Microbial synthesis of gold nanoparticles: current status and future prospects. Adv. Colloid Interf Sci. 2014;209:40-48.

9. Kitching M, Ramani M, Marsili E. Fungal biosynthesis of gold nanoparticles: mechanism and scale up. Microb Biotechnol. 2015;8(6):904-917. doi: 10.1111/1751-7915.12151

10. Du LW, Xian L, Feng JX. Rapid extra-/intracellular biosynthesis of gold nanoparticles by the fungus Penicillium sp. J Nanopart Res. 2011;13(3):921-930.

11. Girard V, Dieryckx C, Job C, Job D. Secretomes: the fungal strike force. Proteomics. 2013;13(3-4):597-608. doi: 10.1002/pmic.201200282

12. Mishra A, Kumari M, Pandey S, Chaudhry V, Gupta KC, Nautiyal CS. Biocatalytic and antimicrobial activities of gold nanoparticles synthesized by Trichoderma sp. Bioresour Technol. 2014;166:235242. doi: 10.1016/j.biortech.2014.04.085

13. Gericke, M., Pinches, A. Biological synthesis of metal nanoparticles. Hydrometallurgy. 2006;83(1-4):132-140.

14. Pimprikar PS, Joshi SS, Kumar AR, Zinjarde SS, Kulkarni SK. Influence of biomass and gold salt concentration on nanoparticle synthesis by the tropical marine yeast Yarrowia lipolytica NCIM 3589. Colloids Surf. B Biointerfaces. 2009; 74(1):309-316. doi: 10.1016/j. colsurfb.2009.07.040

15. Mishra A, Tripathy SK, Yun SI. Bio-synthesis of gold and silver nanoparticles from Candida guilliermondii and their antimicrobial effect against pathogenic bacteria. J Nanosc. Nanotechnol. 2011;11(1):243-248.

16. Tony BD, Goyal D, Khanna S. Decolorization of textile azo dyes by aerobic bacterial consortium. Int Biodeterior Biodegrad. 2009;63(4):462-469.

17. Champagne PP, Ramsay JA. Dye decolorization and detoxification by laccase immobilized on porous glass beads. Bioresour Technol. 2010;101(7):2230-2235.

18. Xu M, Guo J, Kong X, Chen X, Sun G. Fe (III)-enhanced azo reduction by Shewanella decolorationis S12. Appl. Microbiol Biotechnol. 2007;74(6):1342-1349. DOI: 10.1007/s00253-006-0773-z 
19. Chen XJ, Sun GP, Xu MY. Role of iron in azo reduction by resting cells of Shewanella decolorationis S12. J Appl Microbiol. 2011;110(2):580586.

20. Fang Y, Xu MY, Wu WM, Chen XJ, Sun GP, Guo J, et al. Characterization of the enhancement of zero valent iron on microbial azo reduction. BMC Microbiol. 2015;15(1):85.

21. MeenaKumari M, Philip D. Degradation of environment pollutant dyes using phytosynthesized metal nanocatalysts. Spectrochim Acta A. 2015;135:632-638. doi: 10.1016/j.saa.2014.07.037

22. Kim KW. Vapor fixation of intractable for simple and versatile scanning electronmicroscope. J Phytopathol. 2008;156:125-128.

23. Qu YY, Shi SN, Ma F, Yan B. Decolorization of reactive dark blue KR by the synergism of fungus and bacterium using response surface methodology. Bioresour Technol. 2010;101(21):8016-8023. doi: 10.1016/j.biortech.2010.05.025

24. Kalishwaralal K, Deepak V, Pandian SRK, Gurunathan, S. Biological synthesis of gold nanocubes from Bacillus licheniformis. Bioresour Technol. 2009;100(21):5356-5358.

25. Vahabi K, Mansoori GA, Karimi S. Biosynthesis of silver nanoparticles by fungus Trichoderma reesei (a route for large-scale production of AgNPs). Insciences J. 2011;(1):65-79. doi:10.5640/insc.010165

26. Morin sardin S, Nodet P, Coton E, Jany J. Review: Mucor: a janus-faced fungal genus with human health impact and industrial applications. Fun Bio Reviews. 2017;31:12-32.

27. Song JY, Jang HK, Kim BS. Biological synthesis of gold nanoparticles using Magnolia kobus and Diopyros kaki leaf extracts. Process Biochem. 2009;44(10);1133-1138.
28. Kreibig U, Genzel L.Optical absorption of small metallic particles. Surf Sci. 1985;156:678-700.

29. Sujitha MV, Kannan S. Green synthesis of gold nanoparticles using citrus fruits (Citrus limon, Citrus reticulate and Citrus sinensis) aqueous extract and its characterization. Spectrochim Acta A. 2013;102:15-23.

30. Haiss W, Thanh NTK, Aveyard J, Fernig DG. Determination of size and concentration of gold nanoparticles from UV-vis spectra. Anal Chem. 2007;79(11):4215-4221. DOI: 10.1021/ac0702084

31. Bastús NG, Comenge J, Puntes V. Kinetically controlled seeded growth synthesis of citrate-stabilized gold nanoparticles of up to $200 \mathrm{~nm}$ : size focusing versus Ostwald ripening. Langmuir. 2011;27(17):1109811105.

32. Gomi N, Yoshida S, Matsumoto K, Okudomi M, Konno H, Hisabori T, et al. Degradation of the synthetic dye amaranth by the fungus Bjerkandera adusta Dec 1: inference of the degradation pathway from an analysis of decolorized products. Biodegradation. 2011;22(6):1239-1245. doi: 10.1007/s10532-011-9478-9

33. Tan L, Ning S, Zhang X, Shi S. Aerobic decolorization and degradation of azo dyes by growing cells of a newly isolated yeast Candida tropicalis TL-F1. Bioresour Technol. 2013;138:307-313. doi: 10.1016/j. biortech.2013.03.183

34. Dos Santos AB, Cervantes FJ, van Lier JB. Review paper on current technologies for decolourisation of textile wastewaters: perspectives for anaerobic biotechnology. Bioresour Technol. 2007;98(12):23692385. DOI: 10.1016/j.biortech.2006.11.013 